\title{
Smart house: model of resource management and safety of vertical transport
}

\author{
Andrei Prusov ${ }^{1}$, Nadezhda Sevryugina, ${ }^{2, *}$ and Aleksandr Ovsienko ${ }^{2}$ \\ ${ }^{1}$ Yaroslavl state technical university, Yaroslavl, Moskovsky avenue, 88, Russia \\ ${ }^{2}$ Moscow State University of Civil Engineering, Yaroslavskoe shosse, 26, Moscow, 129337, Russia
}

\begin{abstract}
It has been proven that the vertical transport occupies a niche not so much technical objects, how many socially significant technological advances that provide comfort and accessibility for the population of different levels of mobility. Analysis of legal, regulatory documentation showed that the security and reliability of vertical transport is represented in the theory of risk as a scenario of possible events with a broad range of assumptions within the zone of progressing temporary uncertainty and coherence mechanism models of actual conditions, in most cases, it is not. Evaluated scientific elaboration area studies in part integrity, functionality and consistency of the regulatory framework legal enforceability. The model of the complete life cycle of vertical transport. Algorithm of modal analysis of vertical transport parameters of criteria. Estimation of interference and strengthening process factors. Conducted simulation risk factor system the effects of vertical transport the negative socio-economic consequences. Proposed personalized predictive model of full life-cycle operation of vertical transport. Practical recommendations aimed at harmonizing the basic works on scientific and technical support and monitoring, simplification of the development programs of work, obtaining accurate and timely information on the state of vertical transport.
\end{abstract}

\section{Introduction}

Multiple programs of social development of the territories of the Russian Federation are represented by a list of tasks of primary importance. It should be noted, that the improvement of living conditions and the quality of services provided to the population, are one of the key tasks.

Organizational and legal aspects of these issues are governed by regulations, in which the main requirement of the state is to ensure the safety of processes and products for the public. In general, the implementation of these conditions and requirements is faced only with the human factor of the performance quality. At the same time, the technical requires both deep elaboration and detailing of individual positions. It is a question of the technical systems of support for the tasks set, among which the authors distinguish vertical transport as a separate type of technical systems occupying their own, significant niche in the national economics spheres.

\footnotetext{
* Corresponding author: SevryuginaNS@mgsu.ru
} 
The analysis revealed that in the coming years, the question remains maintain the health and safety of technical systems [1-5]. Given the scale and cost of solving the problem, proposes an alternative based on the methodology for the identification and implementation of residual life of technical means for human life support through the implementation of technology modernization, ensuring their continued reliable operation.

From a scientific point of view, the resource technical systems laid down by the manufacturer for the period of operation is reduced and is quantified by the integral value, including the amount of residual resources throughout the circuitry included in the system design. Accordingly, technical systems represent, the element base which is characterized by a random state changes in time, i.e., possessing the characteristics of uncertainty.

To minimize the effect of the time factor is provided by the system of technical maintenance and repair, which is currently quite worked out at normative and technological level allows to support the resource performance in accordance with the technical requirements laid down by the manufacturer.

Developed and introduced in practice of repair facilities recovery methods allow not only $100 \%$ to recover the properties of worn surfaces of the parts, but sometimes, and increase values of properties compared to the original through the use of new technologies and materials.

Because the purpose of repair effects is the maintenance or restoration of the resource (increase in the operational stage of the life cycle of the machine), then such actions can be characterized as resource modernization, aims to minimize the influence of the time factor and maintain the pledged level of quality of the machine.

The analytical results and using the basic application of probability theory generated a number of distributions showing the structure studied, technical systems [5], what can be used structurally and effect or functional block diagram.

Methods of resource modernization is presented in the following stages:

- inspection of facilities-finding of the residual resource and the preparation of structural schemes of reliability;

- assessment of the risk of failure of hardware components for the hierarchical levels of security;

- assessment of the level of moral and physical ageing;

- development of a list of modernization measures with rationale in terms of cost and safety;

- information-methodical and technological support of the project to ensure it is operational prior to the date of disposal.

Currently, vertical transport acquires additional functional characteristics and is a separate classification group of hoisting machines. At the same time, we should understand, that this group includes not only elevators (freight, passenger, hospital, fire, for the disabled, etc.), but also a wide range of hoists (mast, building, facade, for disabled, etc.). The majority of vertical transport types are complex technical devices and have common structural elements [6-10].

\section{Theoretical research}

High-rise construction involves the large-scale usage of vertical transport, which makes it possible to speed up and facilitate the movement of people and goods in space, both during the construction phase and during the operation of the building. Given the high importance of vertical transport, the requirements for regulatory security and reliability are reviewed in accordance with legal and regulatory documentation, regulatory guide. It has been established, that the safety of vertical transport and its systems is assessed by the risk factor of the occurrence of dangerous situations. 
The operation of vertical transport, is a periodic functional loading of parts and a monotonously increasing accumulation of fatigue and wear stresses. They are the cause of failures and the occurrence of undue or dangerous situations, which allows us to accept the hypothesis of their subordination to the Weibull distribution $[5,11]$ when assessing the intensity.

For technical systems, susceptible to wear, the probability of failure-free operation for the Weibull distribution:

$$
R_{t}=\exp \left[-\left(\frac{t}{b}\right)^{k}\right] ; \quad b>0, k>0
$$

where $b$ - Weibull scale distribution; $k$ - Weibull distribution form parameter; $\mathrm{k}>1$ is characteristic for wear.

The essence of the method is reduced:

- to the choice of $n$-th number of subjects (failed) objects (sample size);

- identification of the time of failure $t i$ through the tests;

- determination of the operating time before the $i$-th failure for the censored number of test objects: $r$ - the number of failed objects.

Along with that, a significance level is set, for which the limits of confidence intervals are determined: $\Gamma$ is the significance level (the reciprocal value is the confidence level), is expressed in a percentage value.

$$
b=1-\eta \ln P
$$

where $\eta$ - the shift factor;

$P$ - the probability of a system failure situation.

It should be noted that the importance of play measure of the displacement of the average severity of the manifestations of danger.

The adoption of a multivariate scenario of imitation of a dangerous situation is proved. The situation is conditionally designated by a risk factor parameter with a quantitative indicator $r f\left\{\begin{array}{lll}0 & \ldots & 1\end{array}\right\}$, where 0 is a dangerous situation is not possible; 1 - a dangerous situation is inevitable.

It is possible to establish the factor of influence of approach of a dangerous situation by introduction of the conditional indicator reflecting "event contribution" to safety

$$
B_{i}=P_{i} r f
$$

where $r f=P\left(\Delta_{x} b\left(X_{m}\right)\right)$ - partial derivative of the probability of the dangerous state of the system.

Using the basic provisions of risk theory, when creating the multivariable scenario of a dangerous situation for vertical transport, it is proposed to make a schematic representation of a repetitive three-step method of risk reduction. The formation of the list of constraints for the entire lifecycle of vertical transport is essential.

The first step is functional limitations. The second step is spatial constraints. The third step is technological limitations. Next, the hazards for a specific scenario of development of events at a certain point in the life cycle are identified, after which the risk assessment procedure is carried out.

The disadvantages of this method are its complexity and cost. 
It is proposed to transfer the assessment to the resource validation category, which provides for the use of a personalized algorithm of control actions, based on the results of the computational real time validation methodology of the conditions of operation of vertical transport to meet the criteria of reliability and safety and the requirements of suitability for use under specific conditions.

\section{Model of the full life cycle of vertical transport}

The manufacturer, in the design of new and modernization of existing machines, provides guaranteed safety values, which are a set of accounting for the value of emission made by the machine (list of factors causing abnormal, dangerous situations: noise, vibration, radiation, release of hazardous substances, etc., according to the list of TR "on safety of machinery and equipment).

The presented theoretical and practical results lead to the conclusion that it is necessary to develop a model for the full life cycle of vertical transport (algorithm is shown in Fig.1.). The key criterion for constructing a full life cycle model with a guaranteed level of safety is the information content of the machine functioning parameters, which is used to assess risks.

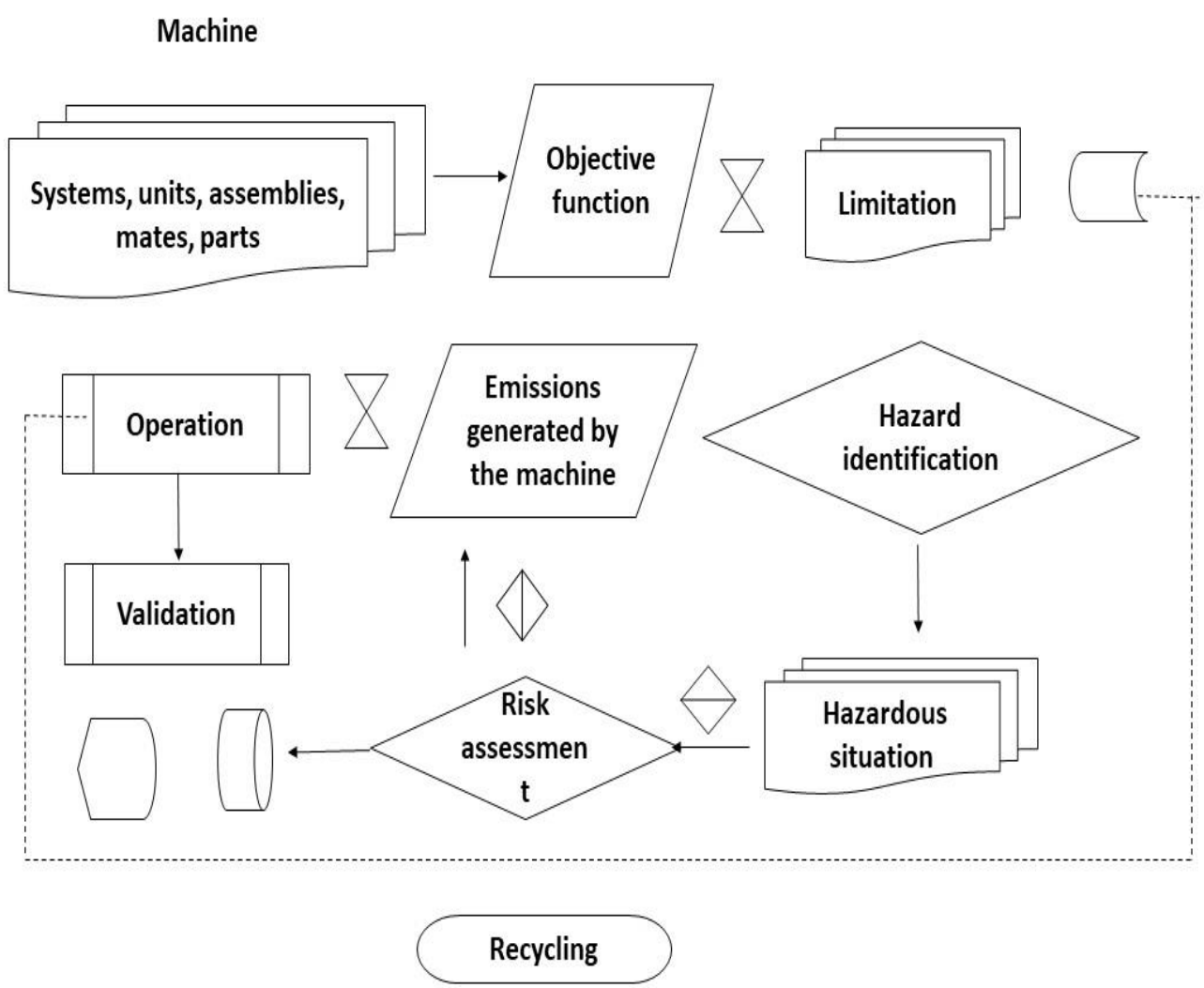

Fig. 1. Algorithm of the full life cycle of vertical transport. 


\section{Experimental studies}

In order to implement the theoretical material into the practical sphere, calculations of the state of the joints and "units" (rope system, drive, car, safety devices, etc.) of passenger and freight-passenger elevators are taken. General regulatory requirements for the parameters of elevators are presented in TR "Safety of elevators" and the relevant standards [6-7].

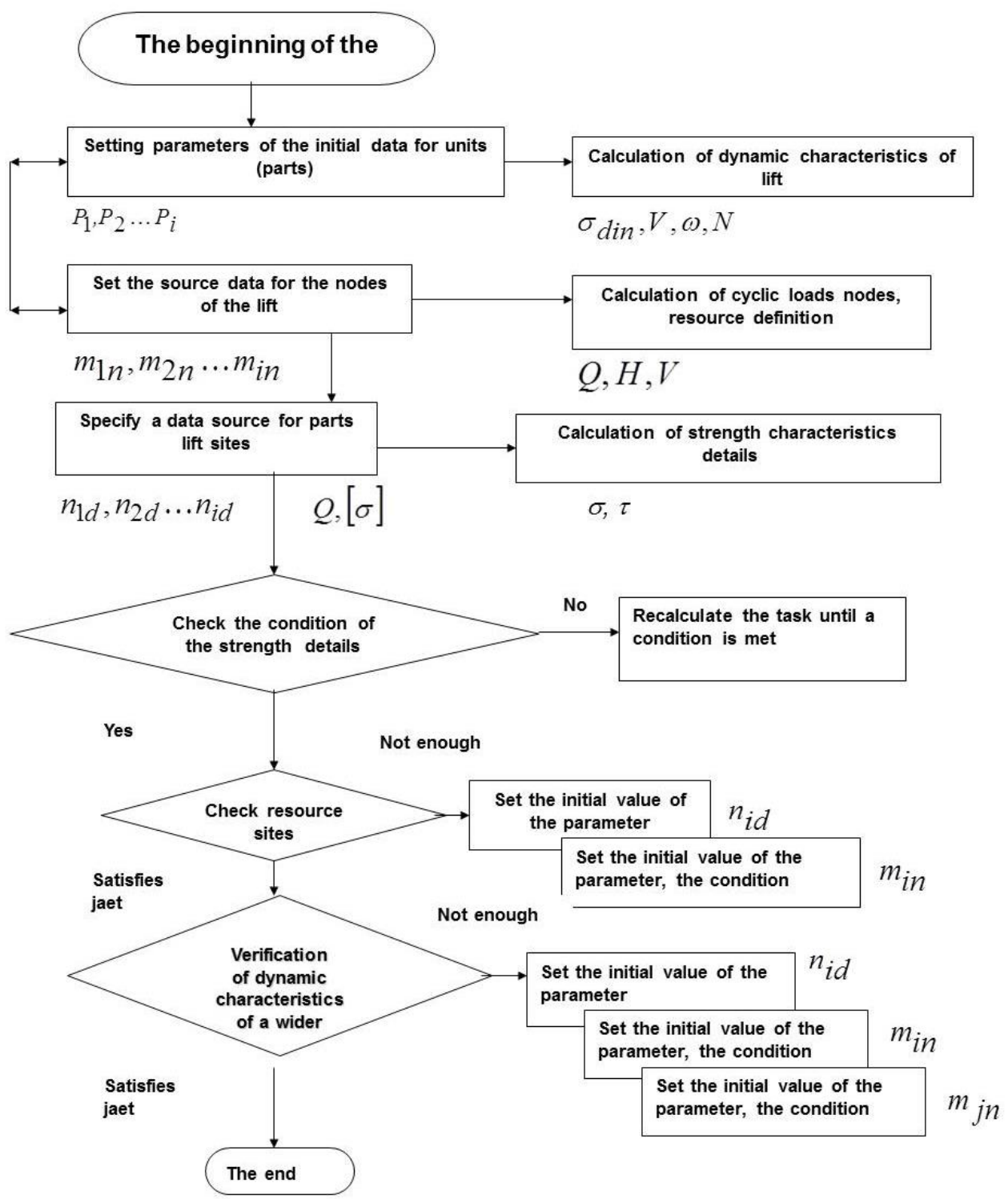

Fig. 2. Algorithm for multivariable calculation of vertical transport parameters taking into account the hierarchical structure.

Statistics were collected from the dispatch stage, which includes 160 elevators in a residential area of a typical city with a population of up to 500,000 people. Data on breakdowns and failures were received through a standard automated supervisory control system, on the basis of user requests. It should be noted that according to statistical data, the 
maximum number of failures (54 cases) per month was associated with a failure of the Elevator shaft door drive. After troubleshooting and analyzing the causes, it is determined that in most cases the failures are not purely technical, but organizational and technical in nature [7].

\section{Algorithm of modal analysis of criterion parameters of vertical transport}

Interpreting the data of technical characteristics of manufacturers of joints, units and machine parts, the algorithm of modal analysis of criteria parameters of vertical transport is made (Fig.2). It provides a multivariable calculation via individual cycles of all structural parts and components of the Elevator (lift), and each component (joint or part) is characterized by individual properties and parameters.

\section{Discussion}

It is proved that vertical transport occupies a niche not so much technical objects as socially significant technical achievements, providing comfort and accessibility for the population of different levels of mobility.

Analysis of legal and regulatory documentation showed, that in the theory of risk, the safety and reliability of vertical transport is presented as a scenario of possible events with a large spread of assumptions falling into the zone of progressive time uncertainty, and the mechanism of coordination of the developed models to real conditions, in most cases, is absent. The relevance of the development of practical recommendations aimed at the unification of the main works on scientific and technical support and monitoring of obtaining reliable and timely information on the state of vertical transport is undeniable [12-19].

\section{Conclusions}

It is proposed to switch to personalized predictive modeling of the full life cycle of vertical transport, with the basic values put in the digital control and management module by manufacturer. The information base is collected into the analytical unit from the hardware throughout the whole period of operation and the self-learning system adjusts the resource values.

\section{References}

1. N. I. Ivashkov, A. Yu. Prusov Hoisting-and-transport case 5-6 (75) 21-24 (2013)

2. S. Yu. Radchenko, A. N. Novikov, A. A. Katunin, M. D. Tebekin J. World of transport and technological machines 1 (36) (2012)

3. A. N. Novikov, A. A. Katunin, M. D. Tebekin J. World of transport and technological machines 4 (31) (2010)

4. E. S. Romanova, P. D. Kapyrin J. MGSU Bulletin 4 (2011)

5. N. S. Sevryugina J. Construction and road machine us 7 (2007)

6. A. Y. Prusov International research journal 1-1 (67) 128-131 (2018)

7. J. J. Saifiddinov, A. Yu. Prusov J. Modernization and scientific research in the transport sector 1 58-61 (2017)

8. N. S. Sevryugina J. Building and road machines 9 (2007)

9. V. I. Telichenko, E. A. Korol', P. B. Kagan, E. N. Kulikova Moscow: ASV (2010)

10. I Prigozhin From existing to arising. Time and complexity in the physical Sciences $M$.: 
Nauka 328 (1985)

11. Zercalov A. I. J. Hoisting-and-transport business 1 35-40 (1999)

12. Janowski 1. Design of mechanical equipment for lifts. Third Edition:-m.: monograph. Publishing House ACU 336 (2005)

13. P. D. Kapyrin and N. S. Sevryugina IOP Conf. Ser.: Mater. Sci. Eng. 451012192 (2018)

14. N. S. Sevryugina J. Advances in Intelligent Systems and Computing 692 273-81 (2018)

15. N. Sevryugina MATEC Web of Conf. RSP. 2600151 (2017)

16. P. D. Kapyrin and N. S. Sevryugina IOP Publishing Ltd 365042018 (2018)

17. S. N. Glagolev, N. S. Sevryugina and A. A. Konev J. The world of transp. and technol. mach. 3 121-5 (2013)

18. E. A. Korol and P. B. Kagan Int. J. Appl. Engin. Res. 10(23) 43456-60 (2015)

19. S. N. Glagolev, S. I. Golovin and N. S. Sevrjugin J. The world of transp. and technol. mach. 4-35 42-45 (2011) 